\title{
Development Status of Classic Photographic Technology under the Background of Contemporary Photography
}

\author{
Yahong Zhao \\ Art and Design School \\ Huanghe Science and Technology College \\ Zhengzhou, China 450000
}

\begin{abstract}
In the film photography age before arriving of contemporary photographic and digital age, the process of photographic technology is completed in three steps. These steps are the whole content of photographic art, but each technology has different requirements on chemical agent combination. Today, various difficulties are overcome by predecessors through unremitting experiments, and people can enjoy the fast image era, but classic photographic technology still reproduced in works.
\end{abstract}

Keywords-contemporary photography; classic technology; photography

\section{INTRODUCTION}

For all people who engage in classic photography at initial stage, they may hold back or even give up due to complex working procedure during technology process. Actually, even the photographer cannot avoid hassling by these procedure complexities at their initial working stage. However, it is relying on these complex procedures that the photography at early stage can be completed. Nowadays, upon retrospection, it is complex craftsmanship that reflects charming of traditional photography. Now, people are used to reading image by fast method, even relying on too much on the fast reading method, such as, viewfinder. How many people can enjoy the special artistic experience and visual and aesthetic feast brought by traditional technology?

\section{History OF Classic PhOtOGRAPHIC TECHNOLOGY}

In BC 5 century, Chinese thinker Mozi first created the pinhole imaging principle, and deeply pondered the light characteristic and image formed by refraction. Thus, the image reflected by light via pinhole is reflection. Westerner Aristotle had ever personally seen the solar eclipse, and then he connected this phenomenon with teaching career, which is shown by darkroom concept in his teaching material [1].

Since the Renaissance Period, pinhole imaging principle began to be explored by artists, architect, scientist and others in their fields. With continuous development and progress of science and technology era, especially for the technology advancement on telescope invention, glass sheet enlargement technology fabrication, scientists begins to put glass sheet in various shapes into pinholes of dark house for further research [2].

In 1816, Joseph Nicéphore Nièpce had acquired the image with technology fabrication in the dark house for the first time. In 1837, Daguerre copperplate photography was found. When Daguerre fixed the image test using chemical material, he come across that hydrargyrum can keep the image immobilization. Thus, he made clear image onto the metallic plate using mercury vapor, so as to keep permanent presentation. In 1866, Peter Henry Emerson published platinum album LIFE AND LANDSCAPES. In his 8 published albums, most of them are platinum photo and only a few are the intaglio printing photos [3]. Among which, the most famous one is Mining Water Lilies "Fig. 1". In 1939, the representative of naturalism photography regarded the year of Daguerre Photography invention as the birth of photography.

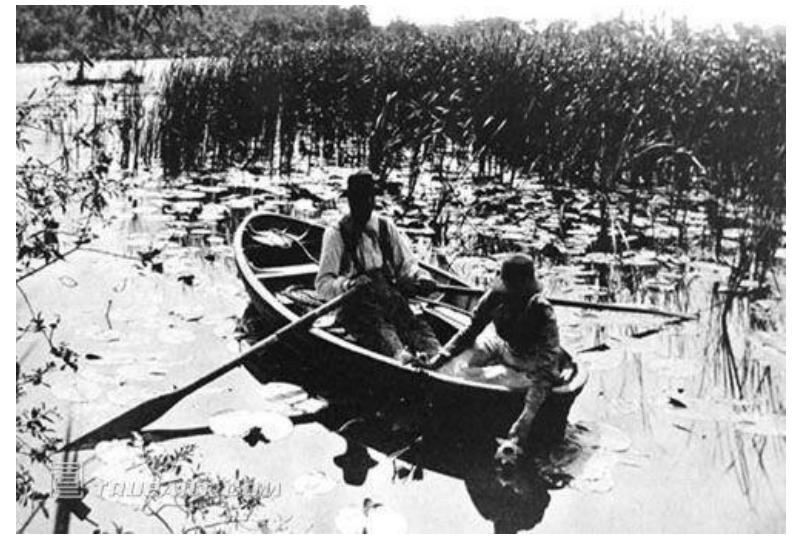

Fig. 1. Mining Water Lilies. Photography: Peter Henry Emerson

After the year of 1980, art culture have new breakthrough, and photography also has its unique performance. Since the period of 1890 s and 1909 s, many classic album prints had successively showed up. To the 21 century, with world and international cultural development, Chinese cultural image has affected the moving of contemporary photography, and appeared on the world historical stage. 


\section{SimilaritiES AND DIFFERENCE BETWEEN ClasSIC PHOTOGRAPHY AND CONTEMPORARY TECHNOLOGY}

Image carrier change is predominated among classic photographic technology and modern technology. From the perspective of photographic development history, as the carrier material of photo, though image carrier is developed from hard to soft plate, the hard carrier photo has earliest hard plate photo and subsequent glass and metallic plate photo [4]. In the initial stage of traditional photography, the image carrier has began to change, which alters from paper medium to cloth, wood, glass, metallic plate, etc. Photographic plate is fabricated by exposing image and fabricating with developer on the glass plate, as the acquired image and taken object image are opposite, this film is also called negative film. This negative film shares the same principle, namely, once reacting with silver ion attached onto film; the silver ion with photosensory will be distributed based on the exposure intensity, resulting in stratified changes of black and white \& gray. Photographer has found that, a wet plate collodion photographic plate with insufficient exposure is negative film. If putting the negative film onto black setting, you can acquire a normal phrase photo along the catoptrics direction [5]. However, though glass plate film is difficult to be stored, it still has unique feature. With trials on fabricating with various medium, for example, plastic material, mobile phone shell "Fig. 2", any slide surface attached with liquor can be used as used as canvas of showing photographers' creation.

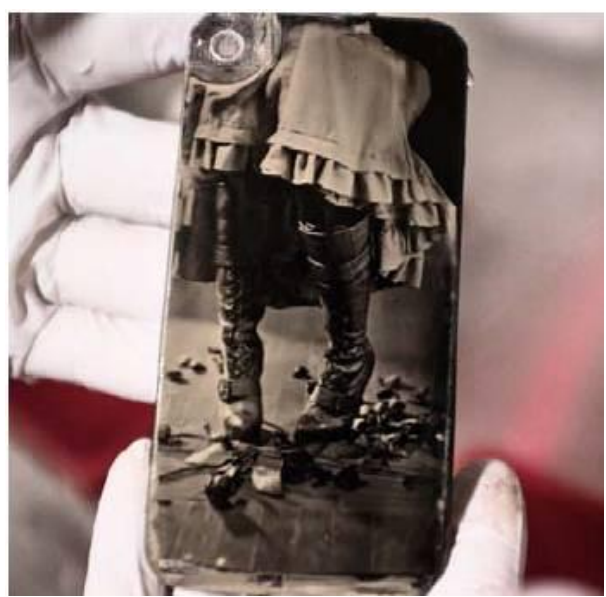

Fig. 2. Captured in the mobile phone shell wet photos. Photography: Jake Potts

There are not only changes of carrier but also liquor formula on the classic photography technology. It is widely accepted by the people, who have better understanding of protein impression craft principle, that the liquor formula includes traditional raw albumen and modern albumen powder, as well as instant protein solution.

Nowadays, any creation photography is available with the development of technology. For the convenience of outdoor creation and timely developer fabrication, photographer refits the truck of vehicle into dark house. Though outdoor shooting is not fresh new, early in the initial stage of photography, field documentary photographer had refitted the carriage into dark house. In this way, walking in the field with driving carriage is similar to the working in the modern vehicle dark house. Compared with photography, vehicle is better to be controlled and can offer more convenience.

\section{CURRENT DOMESTIC SITUATION OF ClasSiC PHOTOGRAPHY TECHNOLOGY}

In China, conservation history on traditional craft is traceable, such as, pottery and porcelain handcraft, cloth dyeing technology, Sichuan brocade, etc. From the perspective of conservation and policies introduction on traditional culture, it shows that demand for culture is increasing in people's lives, and traditional technology has become a key part in people's cultural lives. Since ancient times, people are used to collecting or displaying some traditional crafts to show his aesthetic taste and cultural taste. All this tastes are closely connected with Chinese broad and profound history and culture and interests on antique since ancient times. It seems that, people will feel more exciting if he can collect or display photography with intentional story, for that photography story can not only present onto photo, but also hide into the creation process.

Compared with western photography, Chinese photography starts relatively late, and early photography works in China are also produced by oversea photographer. Rapid development of photography has not been affected by its late beginning. With the research on photography technology and photography device convenience, China has obtained successive progress on photography field.

As in the modern time with digital era rapid development, digital products have been integrated into various aspects of our life. Taking photos has been a living skill for people in modern life, especially for digital photography, it has been one of the most popular and convenient technologies. Unsteadying of original standard, digital technology has been new standard. Likewise, classic photography technology has acquired certain development in China. Wet Sea photographed with classic craft by domestic photographer Di Jinjun "Fig. 3", has exhibited on photographic exhibition and won prize. Frequently exposing classic photography will contribute to the photography ever carrying forward.

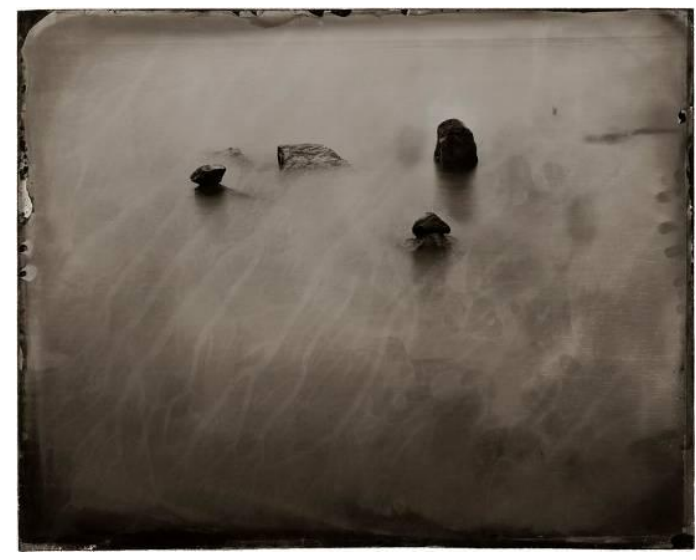

Fig. 3. Wet Sea. Photography: I Jejuna 
In January of 2010, photographer Liu Zheng has established "Family of Chinese Modern Wet Version". In Liu's opinion, this establishment is not sample retro romantic feeling, but also the human nature and aesthetic essence will occurs to our minds with deeply impression [6]. In January of 2010, Hainan Wet Version Photography Club was established, and most of its members are amateurs from folk and varies a lot on ages. When journalist asked the organizer for the reason why they return the photograph craft to the wet version, they answered in this way, many photos were accumulated into the digital camera, but, they'd no idea of which one was their truly love. From this perspective, the true meaning of photography is lost, and the photography process is a thinking course [7].

In recent years, some domestic photographers still regard the classic photograph technology as the creation method. Since the year of 2010 to this year, there are Di Jinjun and Sun Nuo from Beijing, Zhang Hui, Luo Bin, Peng Min and others from Xi'an Technology College have attended the Pingyao International Photography Festival. In these photographers' solo exhibition, the classic craft works were presented, such as, Tomb of Tang Dynasty in Center of Shaanxi Plain, Drug, Traditional Festival, etc., and acquired widely acceptance [8].

Cyanotype series works Tomb of Tang Dynasty in Blue Color "Fig. 2" - "Fig. 4" created by Zhang Hui, reflects the modern conservation and inheritance on historical culture. His photography works are about stone figure surrounding the Shaanxi Tomb of Tang Dynasty. These stone figures left are guarded with metallic cage by the nearby villager, for the ones located in wildness, they are left unattended. The collision between historical relics and cultural heritage protection enlightened the author: it is needed to push the photography technology back to traditional method by combination of historical relics content, and surmount the bubble of fake traditionalism with "westernization, schematization, entertainment, fashion" oriented or new traditionalism on the basis of origin [9]. ocusing on intangible cultural heritage in Tang Mausoleum of Shanxi, the work shows ancient weathered stone sculptures standing in the city, and combines traditional craft-cyanotype, thus forming a visual impact full of strain and charm based on the special characteristics of craft and the mediums. By using unique traditional craft and historical relics, the work well expressed the author's attention on intangible cultural heritage in current cultural background of China. Therefore, it's just the combination of a good theme and the charm of traditional craft that make the work vivid and amazing, and also makes more contemporary artists rethink the source of the work.

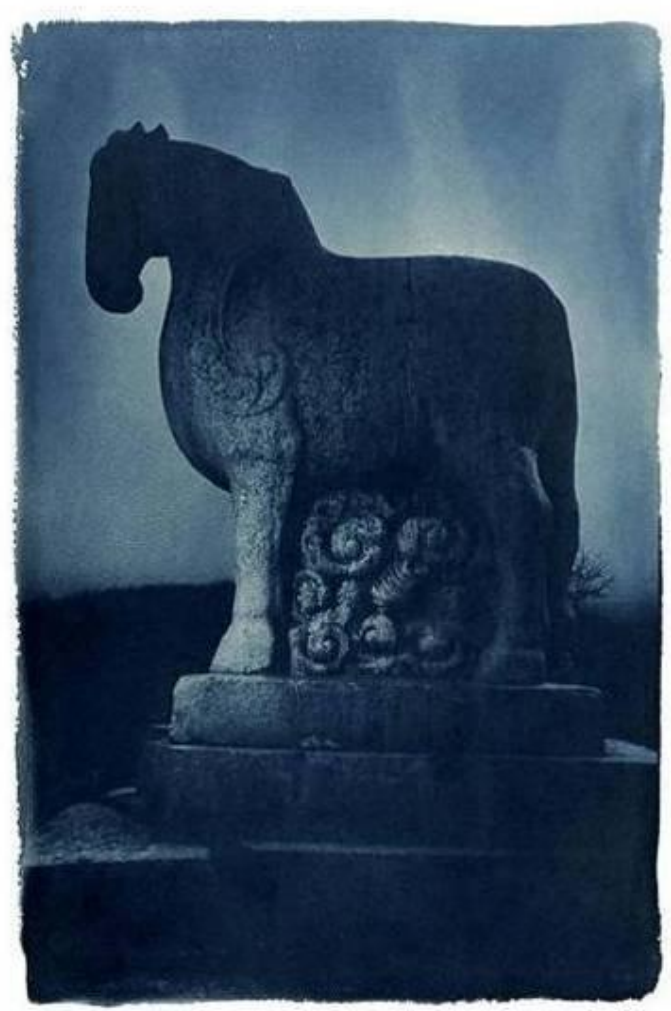

Fig. 4. Tomb of Tang Dynasty in Blue Color. Photography: Zhang Hui

Peng Pin's works Print Traditional Festival Activity "Fig. 5" series aroused people's awareness of developing and protecting traditional festival activity of Longzhou, a kind of traditional culture. By using classic photographic technology- gum bichromate color overlapping, the author can freely select and blend various colors of watercolor to enrich the image with saturate and bright color, which also embodied gorgeous clothes and makeup of traditional festival activity. The author used illusionary motion in photographing so as to make the work full of illusory sense. As the contents of this series of works are mostly derived from the stories about Shaanxi Opera, they are aimed to appeal people to enhance their awareness of protecting and inheriting traditional cultures on the verge of being lost. 


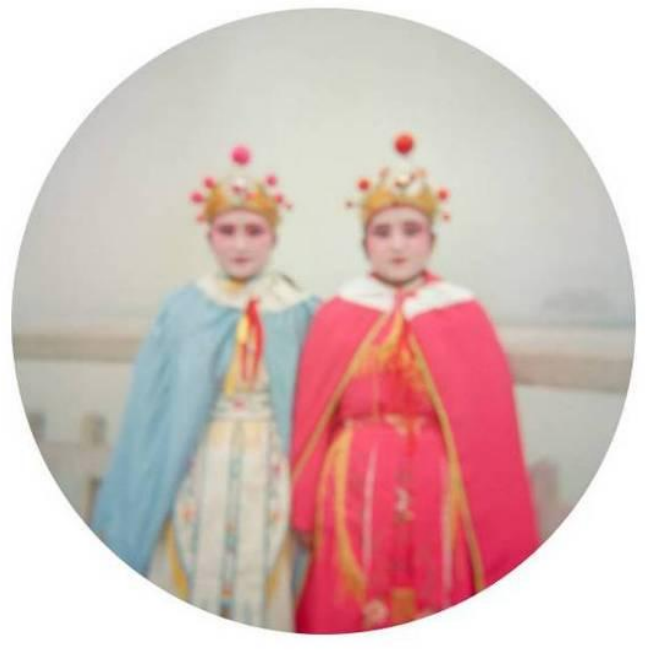

Fig. 5. Print• Traditional Festival Activity. Photography: Peng Min

Originated from the eighteenth century, wet plate processing is an ancient photography technology with complex procedures and experiment-friendly features. In the age of high-speed photography when ten continuous pictures can be got in one second, wet plate processing seems not applicable to the society due to its complex procedures and slow exposure. However, when you finally see the photos through such a complex procedures, you will feel relax and peaceful as well as a little joyful, which is the charm of classical photography and not processed by digital photography. Luo Bin adopted wet plate processing in his work Drug "Fig. 6", perfectly representing objects familiar to us by traditional technology, thereby enabling us to get reflection.

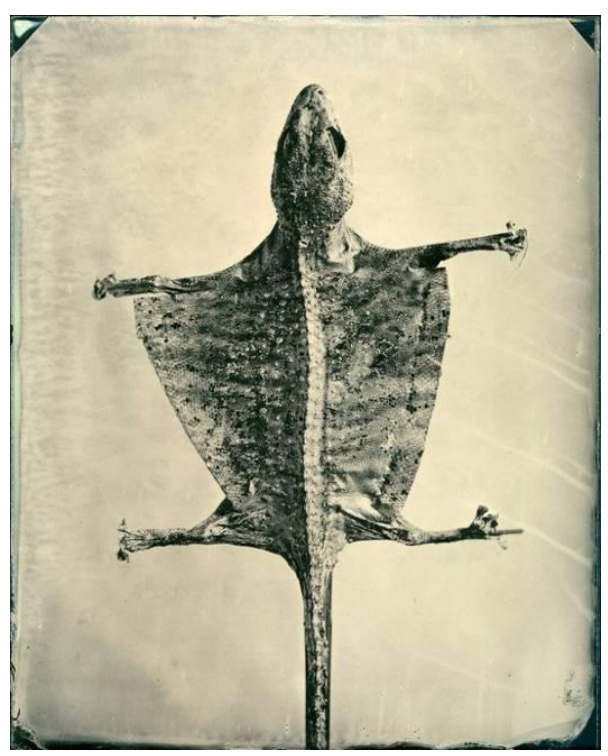

Fig. 6. Drug. Photography: Luo Bin

Shao Wenhuan just used such technology in his works Mildew Green Series "Fig. 7" to produce time illusion, which combines linen, aquatone and darkroom development and are created by many means such as propylene hand painting. By simulating green molds formed on the surface of objects, the works vividly embodied time's corrosivity to objects.

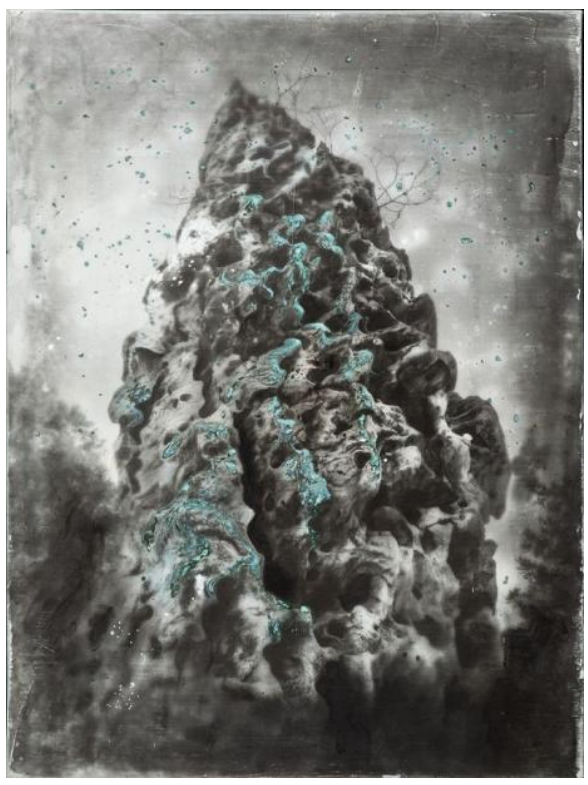

Fig. 7. Mildew Green Series. Photography: Shao Wenhuan

\section{Status QuO OF Classical PHOTOGRAPHIC TECHNOLOGY ABROAD}

Classical photographic technology originated from the middle of 19th century in Europe, including dozens of traditional manual techniques such as wet plate, albumen, blue print, dichromate, etc. These technologies have been invented since born of photography, mainly popular during the thirties of the nineteenth century and of the twentieth century.

Silver Sunshine published in 1965 recorded classical photographic technology of the nineteenth century. Guardian of Light Ray published in 1990 and Times Life published in America recorded early photographic technologies and their application methods. Light Ray and Film introduced the evolution from daguerreo type to photographic paper negative image. All these photographical data have provided solid theoretical foundation and technological guidance [11].

Since the twentieth century, more classical technologies have been valued and collected privatively by artists, including in classical art renaissance period. Photographers have never stopped exploring classical photographical technology on visual form and art language since born of photography [12]. Sally · Man, American photographer, adopted classical photographical technology, especially wet plate process, in most of her Why to Stay series works in 2003. Moreover, Adam Fuss, a contemporary photographic artist in New York representative in researching photogram, occasionally found a piece of negative film on which was nothing but a beam of light as well as the shadow of dusts and particles, then he realized that he had forgot to open the pinhole when taking this picture, and the beam of light was generated from a crack on his camera. It was just this 
mistake that led him to start exploiting photogram. He said, "Studying photogram is aimed at studying inside, not outside, of camera." He adopted large format Cibachrome photographic paper in all his works, enabling them to present extremely bright color, and the most representative one is Love (Love, 1993) "Fig. 8". Susan Derges, an artist of England, produced the picture of the Thames of England by use the purist element-"light", which is also called photogram method, so as to pursue ontological language of photograph. He firstly put a piece of photographic paper in a light- tight container; then put the container in a river at night and removed the cap of the container; last expose the RC paper with preset flashlight. Torben Eskerod, a French artist, used outdated film and developing agent to create a fictional reality, thus intentionally changing winter landscape in winter. All of them have simulated aesthetic deformation on memory (time).

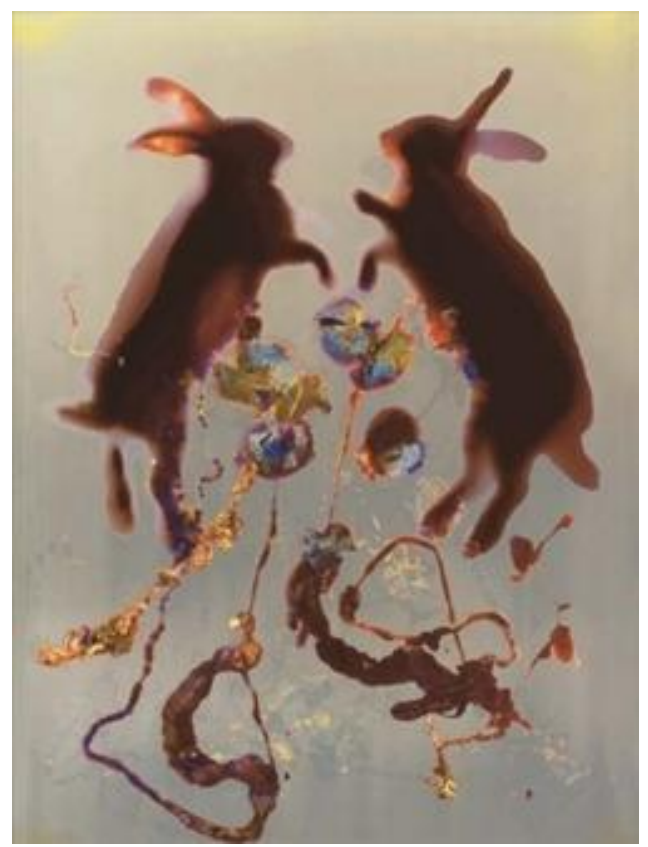

Fig. 8. Love. Photography: Adam Fuss

As contemporary western image is gradually immerged into the artists' concepts and thoughts, and the artists have their own understanding of photograph and have developed their own feature in making images, hence they studied further on creation with traditional technology, having began to break the traditional way of combining shooting and producing with classical technology, but to present a new art creation way by combing classical technology as a medium and contemporary image. These applications are basically derived from the basic characteristic of photographic medium: Physical object can show its image through ray optics and medical effect. Therefore, contemporary arts in the west is unceasingly involved in new fields, constantly innovate and change in form and continuously influence the image of China, proving sufficient study data for enhance of contemporary image.

Most of the works created by Sam Wang during his forty year's photograph teaching periods were arranged and collected in his work Forty Years' Photograph Exploration published in 2010, which can be divided into three parts: The first part consists of pictures of $4 \times 5$ round images created by installing $50 \mathrm{MM}$ wide-angle lens on $5 \times 7$ film camera. Without any cut or post process, the pictures present nature beauty. The second part is called vague vision "Fig. 9", produced by zone plate photograph. As the light ray crosses the concentric circle in a straight line during photographic process, soft halo will appear making his pictures more fantastic. The third part is called multilevel of foldover "Fig. 10 ", as he hasn't found out the accurate location. In addition to using multiple exposure and multi-level developing and printing, Sam Wang has also spent about ten years working on producing color image with silkscreening photography method. By adopting silkscreening photography method, the photographer can select color arbitrarily, so the color in the picture may be different from that of real object. Therefore such works are nonobjective[14]. In late 70s, Sam Wang starts to combine gum bichromate process and other untraditional photographic printing method to process his pictures, which is echoing to his early works in an extent.

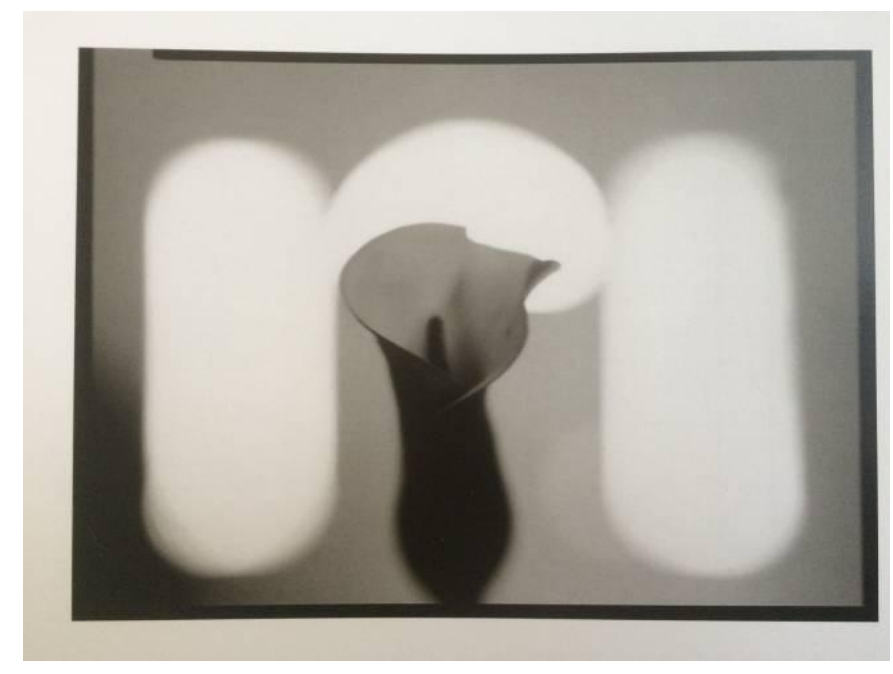

Fig. 9. Photography: Sam Wang

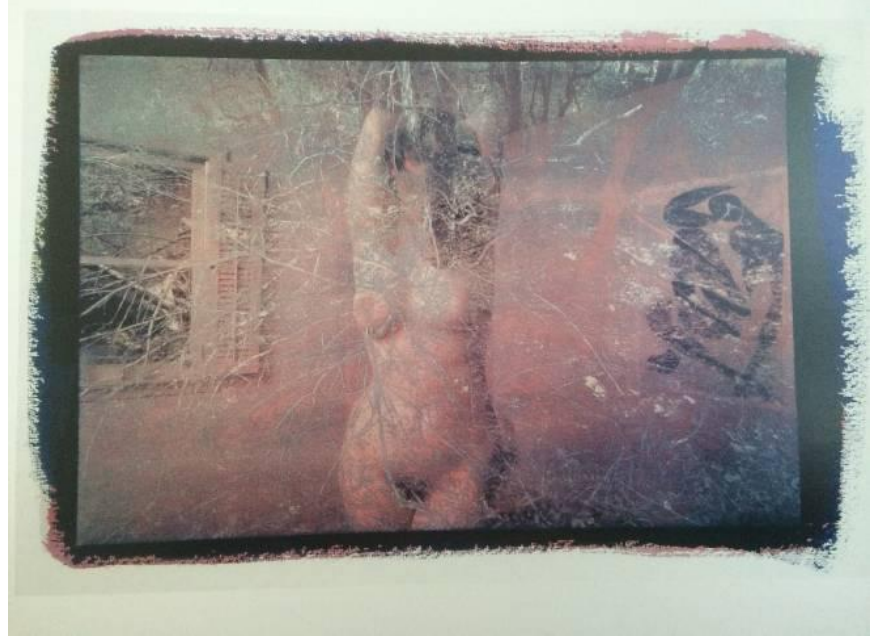

Fig. 10. Photography: Sam Wang 


\section{CONCLUSION}

In contemporary photography circle, few photographic artists begin to pursue authenticity of photography and start new explorations on image art, persistent in exploring and studying traditional technology with practical action. We will have chances to enjoy the charm of images in those days by referring to early photographic data, studying production process of various classic technologies and applying them in our own creation method, and truly restoring the technology of one hundred years ago in recent times.

\section{REFERENCES}

[1] [German] Walter Benjamin. A Short History of Photography (The Work of Art in the Age of Mechanical Reproduce: Benjamin's Theory on Art [M]. Guilin: Guangxi Normal UNIVERSITY Press, March of 2008

[2] [American] Christopher James. The Book of Alternative Photographic Processes [M]. Shanghai: People's Fine Arts Publishing House, June of 2006, page 2

[3] Gu Zheng. A World History of Photography [M]. Hangzhou: Zhejiang Photography Publishing House, July of 2006, page 25

[4] M Langford. World Photography History [M]. Beijing: China Photography Publishing House, 1986. Page 129

[5] Terry Bennett. Photography History of China [M].Shanghai: Shanghai Science and Technology publishing House, 2011.page 66

[6] Shen Hong. Recall of Real Image | Collection and Investment of Old Photos $[\mathrm{M}]$. Shanghai: Shanghai Science and Technology publishing House, 2011.page 25

[7] Liu Zheng. Establishment of Contemporary Wet Plate Process Community of China [EB/OB].http://news.art.net/2010-01-18

[8] Wang You. Why Reuse Wet Plate Process? Wet Plate Process Group of Hainan Island [EB/OB]. Photography of China, 2011 (5) : 8493

[9] Zhang Hui. Literature Study [J].January of 2013.page 155

[10] http://xiaobao.xaut.edu.cn/nr.jsp?urltype=news.NewsContentUrl\&wb newsid $=219688 \& w b$ treeid $=9832$

[11] Broad Road back to Free Photograph" [EB/OB]. http://vision.xitek.com/info/201311/13-138328.html

[12] Li Ling, Wang Zhezi. Cultural World, Discussion on Classical Photography Technology-back to Original Point of Photography [J].June of 2011.page 286

[13] Na Risong, Forward of exhibition of Touch Image of Lin Ran and Jin Ping [EB/OB]. http://biog.sina.com.cn/s/biog5122f8c20100b9j1.html

[14] Gu Zheng. Western Photography Paper Selection [M]. Hangzhou: Zhejiang Photography Publishing House, August of 2007, page 44

[15] Sam Wang. Forty Years' Photography Exploration [M]. Nanjing: Jiangsu Art Publishing House, April of 2010, page 12 